\title{
A Case of Pituitary Hemorrhage Following Cardiopulmonary Bypass Surgery
}

\author{
Ozgen Ilgaz Kocyigit ${ }^{1}$, Serdar Kabatas ${ }^{2}$, Erdinc Civelek$^{2}$, Ezgi Tuncay ${ }^{1}$, \\ Oguz Omay $^{3}$, Tufan Cansever ${ }^{2}$, Ayda Turkoz ${ }^{1}$ \\ ${ }^{1}$ Department of Anesthesiology, Baskent University Istanbul Hospital, Istanbul, Turkey \\ ${ }^{2}$ Department of Neurosurgery, Baskent University Istanbul Hospital, Istanbul, Turkey \\ ${ }^{3}$ Department of Cardiovascular surgery, Baskent University Istanbul Hospital, Istanbul, Turkey \\ E-mail: civsurgeon@yahoo.com \\ Received August 17, 2010; revised November 25, 2010; accepted December 16, 2010
}

\begin{abstract}
A 68-year-old female patient with previous history of transsphenoidal hypophysectomy operation underwent three-vessel coronary artery bypass graft (CABG) surgery for extensive coronary artery disease. Preoperative neurological examination revealed sequelae visual loss at right temporal visual field. Follow-up Magnetic Resonance Imaging studies showed a residual hypophyseal tumor tissue extending to suprasellar area. No additional pathology was detected in the early postoperative cranial control CT, but aggravation of visual field defect was determined. Coincidently, cranial magnetic resonance imaging (MRI) showed hemorrhage into the tumor tissue. We decided to follow-up the patient who exhibited no additional symptoms and was discharged well on the fifth day due to the signs of resolution of hemorrhage. Follow-up controls of the patient at sixth and twelfth months demonstrated normal hormone levels without any additional clinical complaints. We present preoperative assessment, perioperative anesthesia management, and postoperative clinical follow-up of a patient with a residual hypophyseal tumor.
\end{abstract}

Keywords: Anesthesia; Coronary Artery Bypass Graft Surgery; Hemorrhage; Hypophyseal Tumor

\section{Introduction}

Hypophyseal macroadenoma incidence is reported to be 30/100.000 [1]. Regarding infection, radiotherapy, mechanical ventilation, and cardiac bypass surgery (CBP), these tumors may have sudden infarction and hemorrhage [2]. In these complicated cases, the clinical management is sometimes difficult. Pituitary apoplexy occurs spontaneously in $60 \%$ - $80 \%$ cases of asymptomatic patients. Common predisposing factors are head trauma, hypotension, hypertension, pituitary irradiation history, cardiac surgery, anticoagulant therapy treatment with dopamine agonists, pituitary stimulation tests and pregnancy $[1,3]$.

Hypopituitarism developing after coronary bypass surgery, however, is a known phenomenon of rare occurrence [4].One of the favorite pathophysiological mechanisms is the fall of arterial blood pressure induces ischemia and that is followed by infarction of the pituitary gland [5]. A variety of clinical symptoms have been described including headache, fever, lethargy, confusion, obtundation, Addisionian crisis, unilateral ptosis, meiosis, hemiparesis, visual field deficits and ophtalmoplegia $[1,6]$. The ratio of men to women is 10 to 1 in favor of men [1].

\section{Case Report}

The history of the 68-year-old female patient evaluated for elective coronary artery bypass graft (CABG) surgery revealed thyroidectomy, transsphenoidal hypophysectomy, discectomy as well as hypertension and glaucoma. Her laboratory analyses showed low Thyroid Stimulating Hormone (TSH) level (0.128; normal range: 0.27 - 4.2 $\mathrm{uIU} / \mathrm{ml}$ ), normal Triiodothyronine (T3) (2.47; normal range: 1.8 - $4.6 \mathrm{pg} / \mathrm{ml})$, and Thyroxin (T4) (1.33; normal range: $0.9-1.7 \mathrm{ng} / \mathrm{dl}$ ) concentrations. There was no pathology detected in her other laboratory analyses including cortisol and prolactin hormone values. She was under therapy of $5 \mathrm{mg} /$ day prednisolone and $75 \mathrm{mcg} / \mathrm{day}$ levothyroxine. Follow-up Magnetic Resonance Imaging studies showed a residual hypophyseal tumor tissue with 


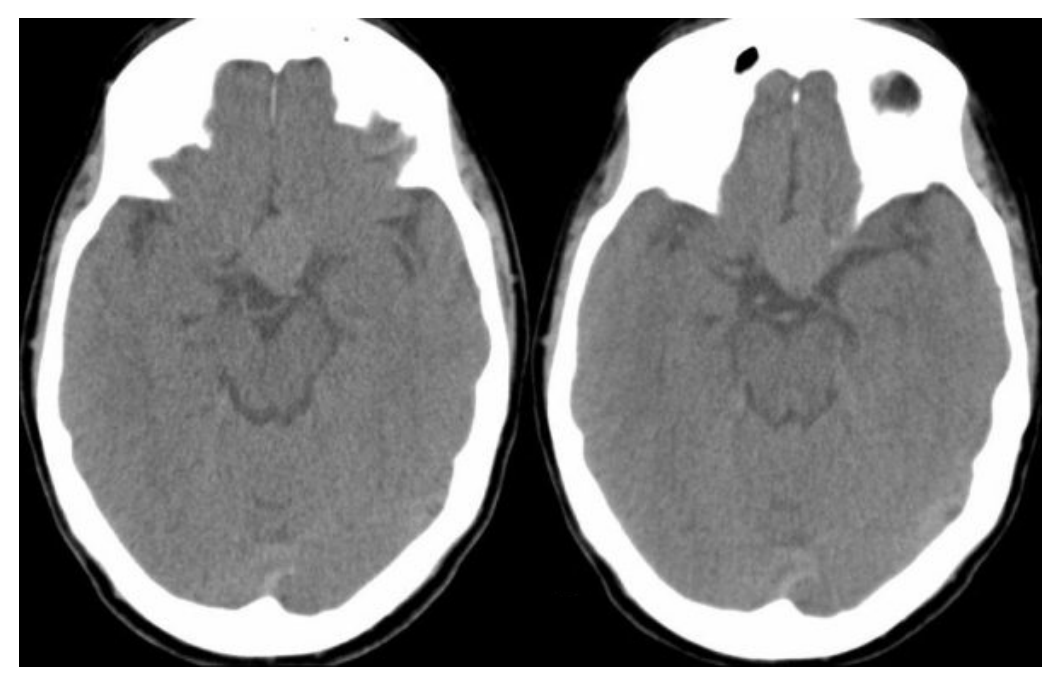

(a)

(b)

Figure 1. (a) Preoperative cranial non-contrast axial CT showed a residual tumor tissue in the sella extending to suprasellar area; (b) there was no additional pathological changes on the postoperative second day cranial non-contrast axial CT.

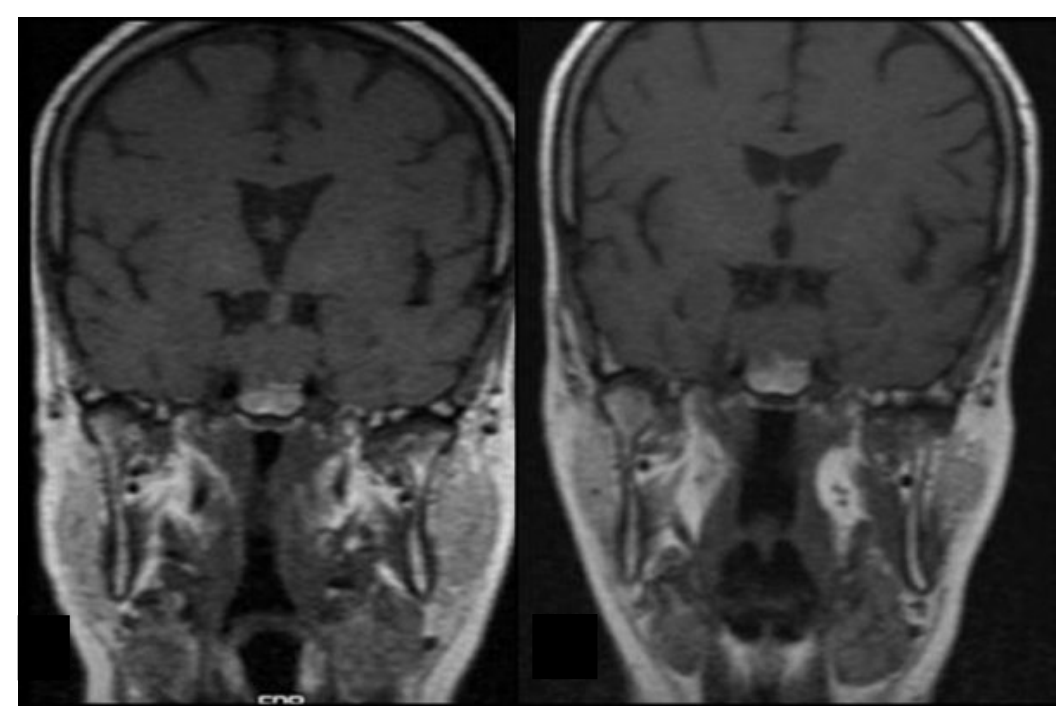

(a)

(b)

Figure 2. (a) Cranial coronal T1-weighted non-contrast MRI demonstrated the hemorrhage into the tumor tissue on the postoperative second day; (b) the intratumoral hemorrhage was slightly resolved on the postoperative tenth day.

regular contour in the sella extending to suprasellar area (Figure 1(a)). Preoperative neurological examination revealed sequelae right temporal hemianopsia.

The patient was premedicated with $3 \mathrm{mg}$ midazolam intravenously. Following radial artery cannulation, induction was achieved by $4 \mathrm{mg} / \mathrm{kg}$ pentothal sodium, 0.8 $\mathrm{mg} / \mathrm{kg}$ vecuronium, and $5 \mathrm{mcg} / \mathrm{kg}$ fentanyl. She had stable vital values and following intubation, her arterial blood pressure (ABP) was 110/44 mmHg, heart rate (HR) was $55 / \mathrm{min}$, and $\mathrm{SpO}_{2}$ was $100 \%$. Anesthesia maintenance was established with $10 \mathrm{mcg} / \mathrm{kg} / \mathrm{h}$ fentanyl, $\mathrm{O}_{2}$-air, and forane 1\% Minimum alveolar concentration (MAC).
After administration of 300 IU/kg heparin, aortocoronary bypass operation was performed via cardiopulmonary bypass (CPB) and cardioplegic arrest. During application of aortic cross clamp for $74 \mathrm{~min}$ and pump for $94 \mathrm{~min}$, respectively, general hypothermia was set at $33^{\circ} \mathrm{C}$. Following $\mathrm{CPB}$, ACT values were restored to basal by delivering $1.3 \mathrm{mg}$ protamine for each $100 \mathrm{IU}$ heparin dose. Under postoperative $5 \mathrm{mcg} / \mathrm{kg} / \mathrm{min}$ dopamine support, she was transferred to the intensive care unit (ICU). Dopamine infusion was discontinued after one hour. She was extubated on seventeenth hour and the following values were observed: ABP, 90/50 mmHg; HR, 60/min; 
$\mathrm{SpO}_{2}, 99 \%$; body temperature, $36.6{ }^{\circ} \mathrm{C}$; central venous pressure, $10 \mathrm{mmHg}$, respectively. No additional pathology was found on the cranial control CT of the patient admitted to the service on postoperative second day; however, aggravation of visual field defect was determined as bitemporal hemianopsia at this time frame (Figure 1(b)). We therefore performed cranial magnetic resonance imaging (MRI) demonstrating hemorrhage into the tumor tissue (Figure 2(a)). We decided to follow-up the patient who exhibited no additional symptoms and was discharged well on the fifth day following signs of resolution of hemorrhage. The control cranial MRI performed on the postoperative tenth day, showed a slight resolution of intratumoral hemorrhage and neurological examination exhibited a decrease in the visual field defect (Figure 2(b)). Follow-up controls of the patient at sixth and twelfth months demonstrated normal hormone levels without any additional clinical complaints.

\section{Discussion}

Hypophyseal apoplexy occurs as a result of the sudden enlargement of adenoma tissue due to edema, hemorrhage and/or infarction. There are many theories about pituitary apoplexy but the pathogenesis still remains unclear. Pituitary tumors are known to bleed 5 times more than other intracranial tumors. According to a theory, enlarged pituitary tumor presses the vascular supply, brings out the ischemia and necrosis both the gland and the tumor. Another theory clarifies that the critical perfusion pressure of the adenomas is below normal gland arterial pressure, so instantaneous changes in perfusion pressure causes the adenoma infarction. Some other theory suggests that the outgrowing of the blood supply because of the tumor enlargement results the ischemic necrosis and secondary hemorrhage $[7,8]$.

Symptoms and signs show up because of compression on parasellar structures, disruption of hypophyseal tissue, and meningeal irritation of blood or necrotic tissues $[9,10]$. In this syndrome, the following clinical symptoms can occur: unilateral or bilateral visual field defect, ophtalmoplegia, endocrinologic imbalance, serious headache, and coma [11]. In cardiac surgery, hemorrhage and infarction may occur in the hypophyseal adenoma during CPB [12]. In the current case, postoperatively presented bitemporal hemianopsia was found to be increased as a result of hemorrhage in the residual tissue. This result was thought to be occurring due to influence of edema, hypoperfusion, and ischemia associated with nonpulsatile flow, on hypophyseal tissue. Cooper et al. reported the specific causes of apoplexy occurring after cardiac surgery as low degree of flow with anticoagulation-re- lated hemorrhage, embolization, hemodilution, ischemia and infarction associated with nonpulsatile flow [11]. The edema of the tissue developed after the CPB, suppresses blood perfusion, damages surrounding tissues, and leads to necrosis. Combination of one or more of those factors may result in development of hypophyseal apoplexy.

The vascular lesions of our patient were not suitable for off-pump surgery; therefore, operation was carried out with CPB. However, off-pump surgery involves use of heparin, and the hemodynamic stability is not as stable as the systemic perfusion pressure established by CPB. Not only CPB, but also heparin administration at low levels during presurgical period, can also lead to this result.

Anticoagulation is known as a precipitating factor but, Levy et al thought that, despite the large number of patients treated with anticoagulation, pituitary apoplexy remained a rare finding [13]. So we all agree that the number of nonsurgical patients who received anticoagulation is much larger than the patients who had Coronary artery By-pass surgery with CPB (cardiopulmonary bypass).

In our case, the residual tumor tissue was present, preoperative hormone concentrations were within normal limits, and drug use was at regular basis. The CBP was well-tolerated, while no hypotensive, hypertensive, or hypoxic condition was observed. The postoperative medical treatment was continued. Regarding neuroanesthesia principles, induction and recovery was achieved through obtaining lowest possible stress response. The cause behind long extubation duration was not a cardiac or hemodynamic problem, but was the aim to avoid any complication that might arise due to occurrence of awakening period in late hours of the day.

Hypophyseal apoplexy cases may present with a fatal course. In order to save the patient and maintain the continuity of visual functions, transsphenoidal decompression may be required $[3,9]$. Previous studies have shown that the outcome of the medical treatment in pituitary apoplexy in stable patients without neuro-ophthalmic deficits is similar to those underwent surgery, but if progressive visual loss is existed, emergent decompression should be considered after medical stabilization to prevent a mortal rebleeding [14]. In our case, surgery was not considered for the hemorrhage within the residual tumor tissue observed on the cranial MRI. Thus, by tenth day, the hemorrhage was started to be resolved and visual field defect was found to be reduced.

\section{Conclusions}

The patients with coronary artery disease are exposed to 
low or high dose anticoagulation during diagnostic or surgical procedures. In cases with hypophyseal adenoma background which are scheduled for graft surgery as per related surgical indications, complications can be minimalized and prevented earlier by performing endocrinologic control in the preoperative period, minimalization of stress associated with perioperative surgery and anesthesia, and close monitoring of the neurological status postoperatively.

The physician should be awake for pituitary adenoma infarction after open cardiac surgery and should remember that, without proper treatment, it can be fatal or cause permanent neurological damage. Surgical and endocrine treatment can be life saving. The outcome depends on early diagnosis and proper intervention.

\section{References}

[1] M. B. Pliam, M. Cohen, L. Cheng, M. Spaenle, M. H. Bronstein and T. W. Atkin, "Pituitary Adenomas Complicating Cardiac Surgery: Summary and Review of 11 Cases,” Journal of Cardiac Surgery, Vol. 10, No. 2, March 1995, pp. 125-132. doi:10.1111/j.1540-8191.1995.tb01230.x

[2] M. Wiesmann, J. Gliemroth, U. Kehler and U. Missler, "Pituitary Apoplexy after Cardiac Surgery Presenting as Deep Coma with Dilated Pupils,” Acta Anaesthesiologica Scandinavica, Vol. 43, No. 2, February 1999, pp. 236238. doi:10.1034/j.1399-6576.1999.430222.x

[3] P. Maccagnan, C. L. Macedo, M. J. Kayath, R. G. Nogueira and J. Abucham, "Conservative Management of Pituitary Apoplexy: A Prospective Study,” Journal of Clinical Endocrinology \& Metabolism, Vol. 80, No. 7, July1995, pp. 2190-2197. doi:10.1210/jc.80.7.2190

[4] L. C. Glass, "Images in Clinical Medicine. Pituitary Apoplexy,” New England Journal of Medicine, Vol. 349, November 2003, p. 2034.

[5] G. Liberale, G. Bruninx, B. Vanderkelen, E. Dubois, E. Vandueren and G. Verhelst, "Pituitary Apoplexy after Aortic Abdominal Aneurysm Surgery: A Case Report," Acta Chirurgica Belgica, Vol 106, No. 1, 2006, pp. 77-80.
[6] Z. Chen, A. W. Murray and J. J. Quinlan, "Pituitary Apoplexy Presenting as Unilateral Third Cranial Nerve Palsy after Coronary Artery Bypass Surgery,” Anesthesia \& Analgesia, Vol. 98, No. 1, January 2004, pp. 46-48. doi:10.1213/01.ANE.0000093233.84896.27

[7] S. Murad-Kejbou and E. Eggenberger, "Pituitary Apoplexy: Evaluation, Management, and Prognosis," Current Opinion in Ophthalmology, Vol. 20, No. 6, November 2009, pp. 456-461. doi:10.1097/ICU.0b013e3283319061

[8] R. N. Nawar, D. AbdelMannan, W. R. Selman and B. M. Arafah, "Pituitary Tumor Apoplexy: A Review," Journal of Intensive Care Medicine, Vol. 23, No. 2, March-April 2008, pp. 75-90. doi:10.1177/0885066607312992

[9] D. C. Bills, F. B. Meyer, E. R. Laws, D. H. Davis, M. J. Ebersold, B. W. Scheithauer, D. M. Ilstrup and C. F. Abboud, "A Retrospective Analysis of Pituitary Apoplexy," Neurosurgery, Vol. 33, No. 4, October 1993, pp. 602-608. doi:10.1227/00006123-199310000-00007

[10] E. R. Cardoso and E. W. Peterson, "Pituitary Apoplexy. A Review,” Neurosurgery, Vol.14, No. 3, March 1984, pp. 363-373. doi:10.1227/00006123-198403000-00021

[11] M. L. Slavin and M. Budubin, "Pituitary Apoplexy Associated with Cardiac Surgery,” American Journal of Ophthalmology, Vol. 98, No. 3, September1984, pp. 291-296.

[12] D. M. Cooper, M. G. Bazaral, A. J. Furlan, E. Sevilla, M. A. Ghattas, L. R. Sheeler, J. R. Little, J. F. Hahn, W. C. Sheldon and F. D. Loop, "Pituitary Apoplexy: A Complication of Cardiac Surgery,” Annals of Thoracic Surgery, Vol. 41, No. 5, May 1986, pp. 547-550. doi:10.1016/S0003-4975(10)63039-1

[13] E. Levy, A. Korach, G. Merin, M. Feinsod and B. Glenville, "Pituitary Apoplexy and CABG: Should We Change Our Strategy?” Annals of Thoracic Surgery, Vol. 84, No. 4, October 2007, pp. 1388-1390. doi:10.1016/j.athoracsur.2007.05.017

[14] R. E. Warwar, S. S. Bhullar, R. J. Pelstring and R. J. Fadell, "Sudden Death from Pituitary Apoplexy in a Patient Presenting with an Isolated Sixth Cranial Nerve Palsy,” Journal of Neuro-Ophthalmology, Vol. 26, No. 2, June 2006, pp. 95-97. doi:10.1097/01.wno.0000223270.01813.57 